\section{Archimedes' fabled sphere brought to life}

\section{Curator recreates a 2,000-year-old model of the Universe.}

\section{BY JO MARCHANT}

$\Lambda$ mechanical model of the Universe attributed to the ancient Greek mathematician and polymath Archimedes has been reconstructed after more than two millennia. The metallic globe, which reproduces the motions of the Sun, Moon and planets across the night sky, is on display for the first time, at a museum in Basel, Switzerland.

The model, built by Michael Wright, a former curator at the Science Museum in London, is largely the product of erudite guesswork. But astrophysicist Mike Edmunds of Cardiff University, UK, says that it is a reminder that geared machines in antiquity were probably more complex than historians often assume.

Several ancient writers and poets describe mechanical models of the heavens ${ }^{1}$, which they often attribute to Archimedes. The earliest and clearest of these appears in a dialogue ${ }^{2}$ written by Roman author Marcus Tullius Cicero in the first century вс. One of Cicero's characters, Philus, describes how the Roman general Marcus Marcellus in 212 BC led an attack on Archimedes' home city of Syracuse (during which the mathematician was killed). As his troops ran the city, Marcellus took only one thing for himself: Archimedes' mechanical sphere.

When Philus later saw a demonstration of the device, he concluded that "the famous Sicilian had been endowed with greater genius than one

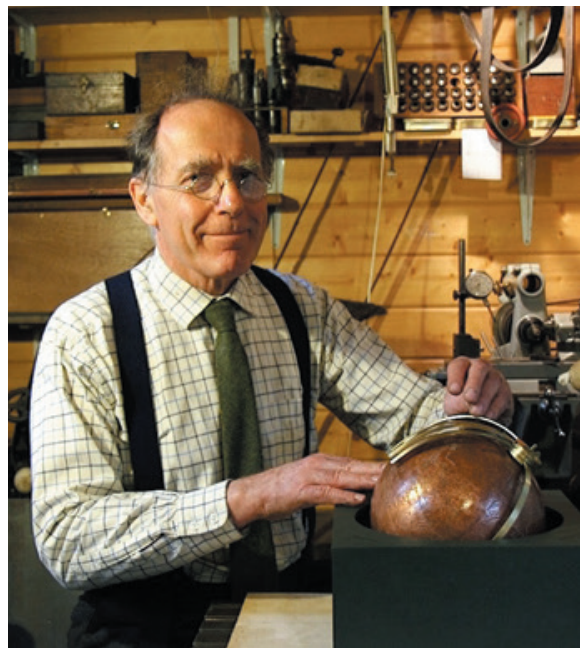

Michael Wright's machine models the heavens.

would imagine it possible for a human being to possess". Solid globes marked with star constellations were common at the time. But Archimedes' invention, Philus notes, also included the Sun, Moon and the five known planets, displaying as it turned "those various and divergent movements with their different rates of speed".

Historians once thought that Cicero's description was fabricated or exaggerated. But studies of a relic known as the Antikythera mechanism, found on a shipwreck from the first century BC, have changed that view. The device turned out to be a clockwork calendar that could model the movements of celestial bodies and predict solar and lunar eclipses - and thus proved that complex geared astronomical devices did exist in antiquity; it consisted of more than 30 bronze gearwheels inside a wooden box the size of a phone book (see Nature 444, 534-538; 2006).

Most specialists have concluded that Cicero was describing a similar machine. But Wright - who has previously built two working models of the Antikythera mechanism - points out that descriptions of Archimedes' device use the Latin word sphaera (sphaira in Greek). "The Antikythera mechanism is not a sphere; it's a shoebox," he says.

Other scholars counter that 'sphere' could have been a generic term for astronomical models, regardless of their shape. But Wright retorts that in Cicero's description, when the globe turned, "the Moon was always as many revolutions behind the Sun on the bronze contrivance as would agree with the number of days it was behind it in the sky". This implies that the device turned once each day, he says, which makes no sense for a flat dial.

Wright built his machine with similar techniques to those that Archimedes might have used. He engraved pictures of the Greek constellations on the surface of the 20-centimetre-wide globe and mounted it in a wooden box, which hides the portion of the globe below the horizon at any given time.

As the globe is turned by hand, 24 gearwheels hidden inside drive curved pointers on the outside. Those marking the Sun and the Moon move at a constant speed, whereas the planets meander, moving back and forth with respect to the fixed stars, just as in the real sky.

No one knows whether Archimedes truly came up with such a device, but Wright argues that he was perfectly positioned to do so. The ancient scholar was a brilliant mathematician and famous for building ingenious machines.

The model is at the Basel Museum of Ancient Art and Ludwig Collection, as part of an exhibition of artefacts from the Antikythera wreck.

1. Edmunds, M. G. Contemp. Phys. 55, 263-285 (2014).

2. Cicero, M. T. De Re Publica Vol. 213 (transl. Keyes, C. W.) 40-44 (Loeb, 1928).

\title{
Maths whizz solves a master's riddle
}

\section{Terence Tao builds on an online collaboration to attack the Erdös discrepancy problem.}

\section{BY CHRIS CESARE}

A maths puzzle that resisted solution for more than 80 years - including computerized attempts to crack it - seems to have yielded to a single mathematician.

On 17 September, Terence Tao, a mathematician at the University of California, Los
Angeles, whose body of work earned him the prestigious Fields Medal in 2006, submitted a paper to the arXiv preprint server claiming to prove a number-theory conjecture posed by mathematician Paul Erdös in the 1930s (T. Tao. Preprint available at http://arxiv.org/ abs/1509.05363; 2015).

“Terry Tao just dropped a bomb," tweeted
Derrick Stolee, a mathematician at Iowa State University in Ames.

Like many puzzles in number theory, the Erdős discrepancy problem is simple to state but devilishly difficult to prove. Erdős, who died in 1996, speculated that any infinite string made up of the numbers 1 and -1 could add up to an arbitrarily large (positive or negative) 